\title{
Study shows more women seeking healthcare in Bangladesh
}

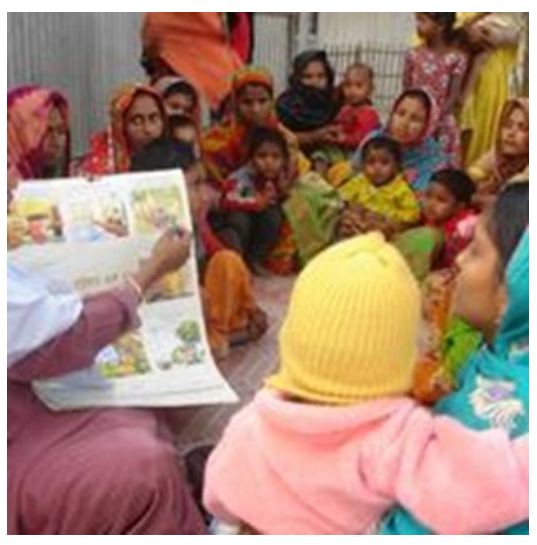

Empowered women take better decisions and make better life choices for themselves and their families. They also help to reverse traditional societal gender-based injustice. Seeking healthcare proactively or participation in decision making on issues related to them and their family is an important indicator of women's empowerment. And, improving healthcare access for girls and women is one of the targets within the UN Sustainable Development Goals gender equality and empowerment of all women and girls - adopted in 2015.

A recent study published in South East Asia Journal of Public Health available online on Bangladesh Journals Online, supported by INASP, analyses women's empowerment in Bangladesh in terms of health-seeking behaviour.

The study conducted by Md. Nazmul Hasan and Prof. M Sheikh Giash Uddin of Jagannath University in Dhaka, Bangladesh has found an improving trend in women's empowerment, particularly in terms of health-related decision making.

Please see the links for details: http://www.inasp.info/en/news/details/247/. 